\title{
Early Repair of Anterior and Distal Hypospadias is less Cmplicable than Delayed Repair
}

\author{
Kibria Golam ${ }^{1}$, Ali Ansar², Hasina Kaniz ${ }^{3}$, Sharifuzzaman ${ }^{4}$, Hoque Imdadul ${ }^{5}$, Nahar Sharmimn ${ }^{6}$
}

\begin{abstract}
Background: Evaluation of the result of early and delayed repair of anterior and distal penile hypospadias. A total number of 144 patients of anterior and distal penile hypospadias with/without chordee were evaluated by follow up study in our hospital and private hospital from January 2010 to July 2013. Redo cases, complex hypospadias and proximal hypospadias were excluded. Simple Random sampling technique was followed to the patients were grouped into Group-A (72 patients) and Group-B(72 patients) on the basis of age of the patients. Both Group-A, age between 6 to 18 months and Group-B, more than 18 month to 14 years were operated by Snodgrass procedure. We did follow up 12- 24 months postoperatvely. It can be recommended for repair of anterior and distal penile hypospadias within 6 to 18 months whenever the question of post urethroplasty cosmosis, wound disruption and formation of urethra cutaneous fistula. [J Shaheed Suhrawardy Med Coll 2015;5(2): 69-72]
\end{abstract}

Keywords: Anterior and Distal Hypospadias is less Cmplicable than Delayed Repair

Received: April 2013; Revised: June 2015; Accepted: October 2013

\section{Introduction}

Hypospadias is a developmental anomaly characterized by a urethral meatus that opens onto the ventral surface of the penis, proximal to the end of the glans ${ }^{1}$. It occurs 1 in 125 live births ${ }^{2}$. Classically three abnormalities are found in the hypospadias penis: 1 . an ectopic opening of the urthral meatus, 2. A ventral curvature of the penis (chordee) and 3. A hooded foreskin on the dorsum of the penis with lack of skin on the ventrum due to a $\mathrm{V}$ shaped defect referred to as' urethral delta'. The chordee and hooded foreskin are not constant, and a hypospadiac meatus may be found under a normally formed prepuce. On the other hand chordee may be isolated without an ectopic urethral opening, which is often associated with a hypoplasia of the corpus spongiosum ${ }^{3}$.

To classify the hypospadias is a tricky job. It is aclassified not according to the original site of meatus, but rather according to the new location of the meatus after correction of chordee. There are anterior $(50 \%)$, middle $(30 \%)$ and posterior penile hypospadias (20\%). Anerior hypospadias includes glanular and subcoronal and middle hypospadias includes distal penile, midshaft and proximal penile hypospadias, posterior variety includes penoscrotal, scrotal and perineal variety of hypospadias ${ }^{4}$. Clinical significance of the hypospadias anomaly is related to several factors. The abnormal location of the meatus and the tendency toward meatal stenosis result in a ventrally deflected and splayed stream. This fact makes the stream difficult to control and often makes it difficult for the patient to void while standing. The ventral curvature associated with chordee can lead to painful erections, especially with severe chordee. Impaired copulation and thus inadequate insemination is a further consequence of significant chordee. Inaddition, the unusual cosmetic appearance associated with the hooded foreskin, flattened glans, and ventral skin deficiency may have an adverse effect on the psychosexual development of the adolescent with hypospadias. All of these factors are evidence that early surgical correction should be offered to all boys with hypospadias, regardless of the severity at the defect ${ }^{5}$.

The object of therapy is to reconstruct a straight penis with a meatus as close as possible to the normal site (ventral of the terminal aspect of the glans) to allow a forward directed urinary stream and normal coitus.

1. Golam kibria, Dept. of Pediatric surgery, Jessore Medical College Hospital, Jessore Bangladesh

2. Md Ansar Ali, Asst. Prof. Dept. of Pediatric surgery, Jessore Medical College Hospital,Jessore Bangladesh

3. Kaniz Hasina, Asc. Prof. Dept. of Pediatric surgery, Dhaka, Medical College Hospital, Dhaka

4. Sharifuzzaman, MS, Consultant Pediatric Surgeon, UHC, Jessore, Bangladesh

5. Imdadul Hoque Raju, DCH,MPH, Civil Surgeon office, Jessore, Bangladesh

6.Sharmin Nahar, Consultant (Gynae \& Obs.), UHC,Chowgacha, Jessore, Bangladesh

\section{Correspondence}

Dr. Golam kibria, Depertment of Pediatric surgery, Jessore Medical College Hospital, Jessore BangladeshEmail; d.malamgir@yahoo.com; Cell No.: $+8801819144934$ 
Several decades ago, surgical repair of hypospadias was considered technically difficult, and the results were often far from optimal. But significant post operative complications make the hypospadias repair challenging. The urethral fistulae are probable most common complication of hypospadias surgery ${ }^{6}$. The Snodgrass technique is becoming more cosmetic than other established technique ${ }^{7}$. The snodgrass urethroplasty provides satisfactory cosmetic and functional results and is versatile in repairing almost all types of hypospadias.

The technical advances are over the past few decades have made it possible to repair hypospadias, in most cases in first year of life. Controversy still exists with regard to the ideal age for repair. The size of the penis before two years is same as that of five years.

The time between 6 to 18 months, within the psychological window in the period of least damage to the infant's psyche. At this age, the infants do not remember and they are also easiest to manage in diapers. Early hypospadias repair help to avoid separation anxiety and castration fears. By using optical magnification, hypospadias surgery can be accomplished safely in early age . $^{8}$

The optimal window recommended for repair when the patient in 6 to 18 months of age. Comparison of normal penile size with age indicates some growth in the first 2 years followed by a relative plateau until puberty. In regard to the development of cognition and sexual identity, less risk is afforded by a procedure occurring in the first year of life?

Surgery during this period precedes the formation of optimal parental child bonding and genital awareness (18 months). Parental anxiety and guilt are also lessened with earlier correction. Postoperative amnesia may be the most valuable asset with this approach. Cosmetic and functional results are better than those in the older child, and postoperative care is easier ${ }^{10}$. In this age group anesthetic morbidity is lower ${ }^{11}$.

\section{Method and Materials}

A total number of 144 patients of anterior and distal penile hypospadias with/without chordee were evaluated by follow up study in our hospital from January 2010 to July 2013. Redo cases, complex hypospadias and proximal hypospadias were excluded. Simple Random sampling technique was followed to select 144 patient were grouped into Group-A (72 patients) and Group-B(72 patients) on the basis of age of the patients. Both Group-A, age between 6 to 18 months and Group-B, more than 18 month to 14 years were operated by Snodgrass procedure by single surgeon.. We did follow up 12- 24 months postoperatvely.

\section{Results:}

In Group-A, good results were obtained in 68 patients $(94.44 \%)$ and only four patients $(5.55 \%)$ developed urthracutaneous fistula and wound disruption in same patient. Two patients of the Group-A developed meatal stenosis. The shape of the glans were normal in appearance most of the cases of this group. The scenario of the results were obtained in Group-B were differ. Eight patients (11.11\%) developed urethra cutaneous fistula, and wound disruptions were more. Eight patients of this group developed meatal stenosis. The shape of the glans were not normal in appearance about nine of the cases in this group. So the result obtained from early repair of anterior and distal penile hypospadias than that of delayed repair, is statically different.

Table-I: Outcome of patients in postoperative period.

\begin{tabular}{l|c|c|c|c}
\hline \multirow{2}{*}{ Complications } & \multicolumn{2}{|c|}{ Group-A(n=72) } & \multicolumn{2}{c}{ Group-A(n=72) } \\
\cline { 2 - 5 } & No & Percentage & No & Percentage \\
\hline Postoperative pyrexia & 3 & 13.63 & 3 & 13.63 \\
Wuond infection & 2 & 9.09 & 2 & 9.09 \\
Wound disruption & 2 & 9.09 & 2 & 9.09 \\
Blackening of ventral skin & 1 & 4.54 & 1 & 4.54 \\
Hematoma in penile shaft & 1 & 4.54 & 1 & 4.54 \\
Stent blockage & 0 & 0 & 0 & 0 \\
Stent dislodgement & 1 & 4.54 & 1 & 4.54 \\
\hline
\end{tabular}

There were multiple complications persisted in same individual.

Table-II: Complications in patients in post discharge

\begin{tabular}{|l|l|l|l|l|l|l|}
\hline Shape of the glans & \multicolumn{2}{|c|}{ Group-A(n=72) } & \multicolumn{4}{|c|}{ Group-A(n=72) } \\
\cline { 2 - 7 } & $1^{\text {st }} \mathrm{FU}$ & $2^{\text {nd }} \mathrm{FU}$ & $3^{\text {rd }} \mathrm{FU}$ & $1^{\text {st }} \mathrm{FU}$ & $2^{\text {nd }} \mathrm{FU}$ & $3^{\text {rd }} \mathrm{FU}$ \\
& $($ After & (After & (After & (After & (After & (After \\
& 1 week) & 1 month) & 3 months) & 1 week) & 1 month) & 3 months $)$ \\
\hline Pyramidal/Conical & 68 & 68 & 68 & 60 & 60 & 60 \\
Depressed/Flatened & 4 & 4 & 4 & 10 & 10 & 10 \\
Meatal stenosis & $9.09 \%)$ & $(9.09 \%)$ & $(9.09 \%)$ & $(27.72 \%)$ & $(22.72 \%)$ & $(22.72 \%)$ \\
Urethral stricture & 0 & 2 & 2 & $3(13.63)$ & $8(18.18)$ & 8 \\
U-C fistula & 4 & 0 & 1 & 0 & 8 & 8 \\
\hline
\end{tabular}

$\mathrm{F}$ test is done for significant of in wound disruption, cosmesis and U-C fistula for both group A and group B

For wound disruption calculated value 0.224 is less than tabulated value $(\mathrm{p}>0.05)$;

For U-C fistula calculated value 1.612 is less than tabulated value $(\mathrm{p}>0.05)$;

For cosmesis calculated value 1.73 is less than tabulated value ( $>0.05)$.

So the difference is statically significant.

The surgical outcome of hypospadias surgery between group-A and group-B is significant.

\section{Discussion}

In this study, 144 patients of age ranging from 6 months to 14 years were included. In group- $A$, mean age of the patients was 11 months and in group-B, mean age was 8.5 years. The time between 6 to 18 months, within the 
psychological window in the period of least damage to the infant's psyche. At this age, the infants do not remember and they are also easiest to manage in diapers. Early hypospadias repair help to avoid separation anxiety and castration fears.. By using optical magnification, hypospadias surgery can be accomplished safely in early age.

The optimal window recommended for repair when the patient in 6 to 18 months of age. Comparison of normal penile size with age indicates some growth in the first 2 years followed by a relative plateau until puberty. In regard to the development of cognition and sexual identity, less risk is afforded by a procedure occurring in the first year of life .

Surgery during this period precedes the formation of optimal parental child bonding and genital awareness (18 months). Parental anxiety and guilt are also lessened with earlier correction. Postoperative amnesia may be the most valuable asset with this approach. Cosmetic and functional results are better than those in the older child, and postoperative care is easier. In this age group anesthetic morbidity is lower.

The abnormal location of the meatus and the tendency towards meatal stenosis result in a ventrally deflected and splayed stream of urine in hypospadias. Mild to moderate or severe form of meatal stenosis may be associated with any variety hypospadias. In this series, 2 patients $(9.09 \%)$ in group-A and $4(18.18 \%)$ in group-B presented with meatal stenosis. The size of the meatus and the quality of the surrounding supportive tissue as well as the configuration of the glans are quite variable and ultimately determine the surgical procedure.

Hypospadias may be associated with inguinal hernia (9\%) or undescended testis $(13 \%)$, with a higher incidence when the meatus is more proximal location.. In our observation, two patients were associated with operated undescended testis.

In this study, both groups of hypospadias patients urethroplasty was done by Snodgrass procedure. The mean operating time was $69.67 \pm 6.94$ minutes in group-A and $60.33 \pm 5.1$ minutes in group $-\mathrm{B}$. There was significant difference in mean operating time .The mean difference between groups showed statistically significant difference. However, the mean time of urethroplasty without any optical magnification seems to be much shorter, but by doing operation at early age may prevent a second surgery.

PVC feeding tube was used as urethral stent and diversion of urine which was kept for 8 days after urethroplasty. However, one patient in group-B the urethral stent was blocked with clot in 1st postoperative day, but it was dissolved after flushing with normal saline. Another one patient developed hematoma, which subsequently resolved after a week. Two patient in group-B accidentally dislost their stent on 6 th postoperative days. We did not attempt to reposition the stent as it might cause serious danger to anastomotic site. Chatterjee et al, 2004 suggested reintroduced the stent, if it dislost early of the postoperative days. There was blackening of the ventral skin of the penis in two patients of group-B. Possibly it was due to the loss of vascularity of ventral skin during taking the dartos flaps from the penile skin.
In this study. There was found postoperative meatal stenosis in two patients in group-A and five patients in group-B on 2nd and 3rd postoperative follow up. There were advised for regular meatal dilatation with the nozzle of neomycin eye ointment and become improved.

In this study, urethra-cutaneous fistula developed in six $(13.63 \%)$ patients, $2(9.09 \%)$ patients in group-A and 4 $(18.18 \%)$ patients in group-B. It is competent to the internationally accepted rate of fistula formation in defferent age group patients.

In group- A, average age of the patients were 11 months. Good results were obtained in 20 patients $(90.90 \%)$ and only two patients $(9.09 \%)$ developed urethra cutaneous fistula, and wound disruption developed in same patients. Two patient of the Group-A developed meatal stenosis . The shape of the glans were normal in appearace most of the cases of this group.

In roup- B, average age of the patients were 8.5 years . 4 patients (18.18\%) developed urethra cutaneous fistula, and wound disruption were more than other group of patients. In Group-B five patients developed flattened glans and four of them developed meatal stenosis.

In hypospadias the ventral aspect and coronal area has less subcutaneous tissue. The distal portion of the urthra is usually not covered by adequate corpora spongiosa and adheres to penile skin with minimal subcutaneous tissue. When repaired, urethra is covered with ventral skin with insufficient subcutaneous tissue and the chance of fistula formation is considerable. The dartos fascia increase the vascularity and act as a protecting subcutaneous tissue over the neourethra.

By comparing the surgical outcome of urethroplasty is statically significant at early repair (6-18 months) than delayed repair ( $>18$ months to 14years).

This study demonstrates that the early repair is more effective in terms cosmosis, reduced wound disruption and urethra-cutaneous fistula formation than that of delayed repair.

\section{Conclusion}

The result of early repair is better in comparison to delayed repair of anterior and distal penile hypospadias, the present study confirms the lower rate of depressed or flattened appearance glans, wound disruption and urethra cutaneous fistula formation. Thus it can be recommended for repair of anterior and distal penile hypospadias whenever the question of post urethroplasty cosmosis wound disruption and urethra cutaneous fistula come in the list of complications.

\section{References}

1. Murphy Jp, 2000: Hypospadias, in Paediatric Surgery, 3rd Edition, PP 763-782

2. Laurence S. Baskin 2006, Hypospadias, Pediatric surgery, 6th Edition PP, 1870-1898

3. Mouriquand, PDE, Mure, PY, 2001, 'Hypospadias', in Pediatric Urology, Gearheart, Jp, Rink, RC, Mouriquand, PDE, WB. Saunders Company, Philadelphia, pp 763-782.

4. Duckett, JW, Kaplan, GW, Woodward, JR, Devine, CJ, Jr, 1980, 'Panel: Complications of hypospadias repair' Urol. Clin. N. Am, vol.7,pp.443-454 5. Murphy Jp, 2000: Hypospadias, in Paediatric Surgery, 3rd Edition, PP 763-782 
6. Alan B Retik MD, Michael, Keating and James Mandell 1988,Complication of hypospadias repair. Uro clinics of North America vol15, No.2.

7. Moschos Ververidis, Alan P. Dickson, David C.S Gough; 2005. An objective assessment of the results of hypospadias surgery. BJU International 96 (1), pp. 135-139.

8. Jeffery Wacksman,1984 : Results of early hypospadias surgery using optical magnification. J. Urol

9. Schultz, JR, Klykylo, Wm, Wacksman, J.,1983, Timing of elective hypospadias repair in children', Paediatrics, vol,71 pp 342-351.

10. Alan B. Retik, Joseph G. Borer 1998: Primary and reoperative hypospadias repair with the Snodgrass technique. World J. Urol, vol. 16, pp. 186-191.
11. Jay L. 2006 Grossfeld Pediatric surgery 6th Edition. With hypospadias', Urol. Clinic. N. Am vol.8 pp565-571

12. Schultz, JR, Klykylo, Wm, Wacksman, J.,1983, Timing of elective hypospadias repair in children', Paediatrics, vol,71 pp 342-351

13. Retik, AB, Keating, M, Mandell, J. 1988, Complication of hypospadias Surgery' Urol Clin. N. Am. Vol.15, pp223-226.

14. Duckett. JW, 1991 : 'hypospadias repair', paediatric urology, (ed) O’Donnell.B,3rd ed, Butterworth co. Surrey, England.1893-1918.9 15. Browne, D 1953 'A comparison of the Duplay and Denis browne techniques for hypospadias operations’, Vol .34, pp787-793. 